\title{
IGRAÇÃo lateral de PeiXes e A VULnerabilidade dA baía do Chacororé, pantanal de Barão de Melgaço, Mato Grosso, Brasil
}

\author{
Nelson Antunes de Moura
}

Universidade do Estado de Mato Grosso, Campus Universitário de Tangará da Serra, Departamento de Ciências Biológicas, Rod. MT 358, km 07, Jardim Aeroporto, Tangará da Serra-MT, nelsonmoura@unemat.br

\author{
Adalberto Luis Val \\ Pesquisador, INPA/MCTIC, Av. André Araújo 2936, Manaus, Amazonas, Brasil
}

\begin{abstract}
Resumo: Migrações laterais são movimentos realizados por peixes que se deslocam em cardumes para a ocupação de ambientes lênticos e/ou lóticos, para alimentação, reprodução ou buscar condições favoráveis de sobrevivência. Este estudo foi realizado no corixo Manoel Isaac, que conecta o rio Cuiabá à Lagoa do Chacororé, no Pantanal de Barão de Melgaço, Estado de Mato Grosso. Foram realizadas coletas no período de abril a dezembro, nas estações de vazante, seca e enchente para determinar os movimentos migratórios laterais dos peixes. Determinou-se que 12 espécies utilizam os sistemas em duas épocas bem definidas: vazante e enchente, para os comportamentos alimentares (época da "lufada") e para o comportamento reprodutivo (época da "piracema"), respectivamente. Quando o nível da água é mais elevado, ocorre a passagem dos peixes entre o rio e a baía e vice-versa. No início da vazante (abril), a captura é elevada, indo até o mês de julho, e as capturas por unidade de esforço (CPUEs) decrescem quando tem início o período de estiagem (julho) e ocorre a elevação do nível da água do corixo no final de setembro. Uma segunda elevação na captura é verificada, porém, o sentido de movimentação da maioria das espécies é a favor da correnteza, ou seja, movimento de entrada na baía. Conclui-se que a migração lateral de peixes entre a baía Chacororé e o rio Cuiabá durante o estudo apresentaram tendências de movimentos, para as maiores capturas, durante os meses de abril a junho (vazante) com sentido de movimentação baía-rio e, durante a enchente (outubro a dezembro), o sentido do movimento dos peixes é rio-baía.
\end{abstract}

Palavras-chave: Ambiente lótico, ambiente lêntico, conectividade rio-baía, ictiofauna.

\section{Lateral migration of fishes and vulnerability of Chacororé lake, Pantanal of Barão de Melgaço, Mato Grosso states, Brazil}

Abstract: Lateral migrations are movements of fish schools to and from lentic and/or lotic environments, in order to feed, reproduce or seek favorable survival conditions. This study was conducted in the corixo Manoel Isaac, which connects Cuiabá River to Chacororé Lake in the Pantanal of Barão of Melgaço, State of Mato Grosso. Fish were collected in the period of April-December, that included the seasons of receding water, drought and flood aiming to analyze the lateral migration of fish. It was observed that 12 species used the systems during dry and flood seasons, to feed (time of "lufada") and to spawn (time of "spawning"), respectively. When the water level is higher, the fish migrate from the bay to the river. At the beginning of the ebb (April), the catch is high, extending up to July, and CPUEs decrease when the drought period begins (July) and there is a rise in the water level of the corixo at the end of September. A second elevation in the catch is verified; however, the direction of movement of the majority of the species is from the river to the bay, following water current. It was concluded that the lateral migration of fish between the Chacororé Bay and the Cuiabá River during the study presented greater catches during the months of April to June (ebb) with fish moving from the bay to the river and during the flood (October to December), the fish migrate in the opposite, from 
the river towards bay.

Keywords: Lotic environment, lentic environment, River-bay connection, fish fauna.

\section{INTRODUÇÃO}

As migrações sazonais de peixes são aquelas realizadas por movimentos longitudinais ao longo dos principais corpos d'água, enquanto as migrações laterais se realizam entre o rio e a área alagável, geralmente envolvendo pequenas distâncias (Welcomme, 1985). Lowe-McConnell (1977) citou que, durante a enchente, muitas espécies realizam movimento lateral para dentro da planície de inundação e retornam ao canal principal durante a diminuição do nível da água. O mesmo comportamento é citado por vários outros autores em regiões como a África (Chapmam et al., 1971), América do Sul (Bayley, 1973), Amazônia (Ribeiro, 1983; Junk, 1984; Zaniboni Filho, 1985). No Pantanal Mato-grossense, os principais movimentos migratórios (migrações sazonais) de peixes são denominados "piracema" e "lufada", nos quais participam diversas espécies de pequeno e grande porte. 0 movimento rio acima é realizado pelos adultos, de maio a outubro, durante o período de seca, e em novembro e dezembro, quando o nível começa a subir, ocorre a piracema, sendo que os jovens e os adultos reprodutores após a reprodução (rodada), penetram nas áreas permanentemente alagadas.

No final de março e início de abril, quando cessam as chuvas, os peixes adultos bem alimentados retornam ao rio, comportamento este denominado de lufada (migração lateral para o ambiente lótico) e, neste momento, os jovens realizam movimentos laterais para os alagados permanentes, chamados de baías, local em que se completa o crescimento até a fase de início da maturidade sexual (Ferraz de Lima, 1986/87).

No Pantanal, acredita-se que a maior influência nos movimentos migratórios em peixes são as flutuações no nível da água, que proporcionam um aumento nas áreas para a alimentação, refúgio, abrigo e que as condições desfavoráveis em determinadas épocas do ano servem como estímulo para que algumas espécies abandonem um ambiente e invadam outro com características ambientais e biológicas diferentes, mas que, em longo prazo, criariam benefícios que permitiriam uma maior taxa de sobrevivência.
Val (1986) afirmou que mudanças muito bruscas no oxigênio dissolvido forçam rápidos ajustes respiratórios nos animais aquáticos, especialmente nos peixes. Segundo o autor, a resposta comportamental mais simples e imediata à depleção de oxigênio dissolvido é a fuga do ambiente.

A produção da pesca do rio Cuiabá é sustentada pela captura e comercialização de peixes migradores. A manutenção dos estoques pesqueiros só poderá ser assegurada se houver cuidados com as zonas de inundação, como os alagados e, principalmente as "baías" (lagos perenes, permanentemente ou não conectados ao rio), os quais funcionam como berçários naturais responsáveis pela fase inicial de crescimento dos peixes reofílicos.

Conhecer a resposta comportamental da migração lateral é de fundamental importância para o entendimento da estrutura e funcionamento das comunidades ícticas do Pantanal. Neste estudo objetivou-se contribuir para a compreensão da dinâmica, vulnerabilidade da baía do Chacororé e as tendências de movimentos migratórios dos peixes, particularmente das espécies que realizam a migração lateral entre o rio Cuiabá e a baía do Chacororé, no sub-pantanal de Barão de Melgaço.

\section{Material e métodos}

A área estudada localiza-se no Pantanal de Barão de Melgaço, município de Barão de Melgaço (16011'39"S, 56014'45"W), a 132 metros de altitude, sub-pantanal de Barão de Melgaço (Fig. 1). A bacia do rio Cuiabá apresenta aproximadamente 22.000 km2 e sua porção Sul é ocupada por extensas planícies (terras baixas e planas), constituindo o Pantanal Matogrossense (Salomão, 1999). O rio Cuiabá, com uma extensão de 850 $\mathrm{km}$, tem como principais tributários os rios Manso, Aricá-Mirim, Aricá-Açu e São Lourenço, cujas nascentes estão localizadas nos planaltos, que circundam a porção nordeste do Pantanal Mato-grossense (Severi, 1999).

Durante o mês de abril a dezembro de 1999, foram feitas análises físicas e químicas da água para verificar se as variações dessas variáveis 


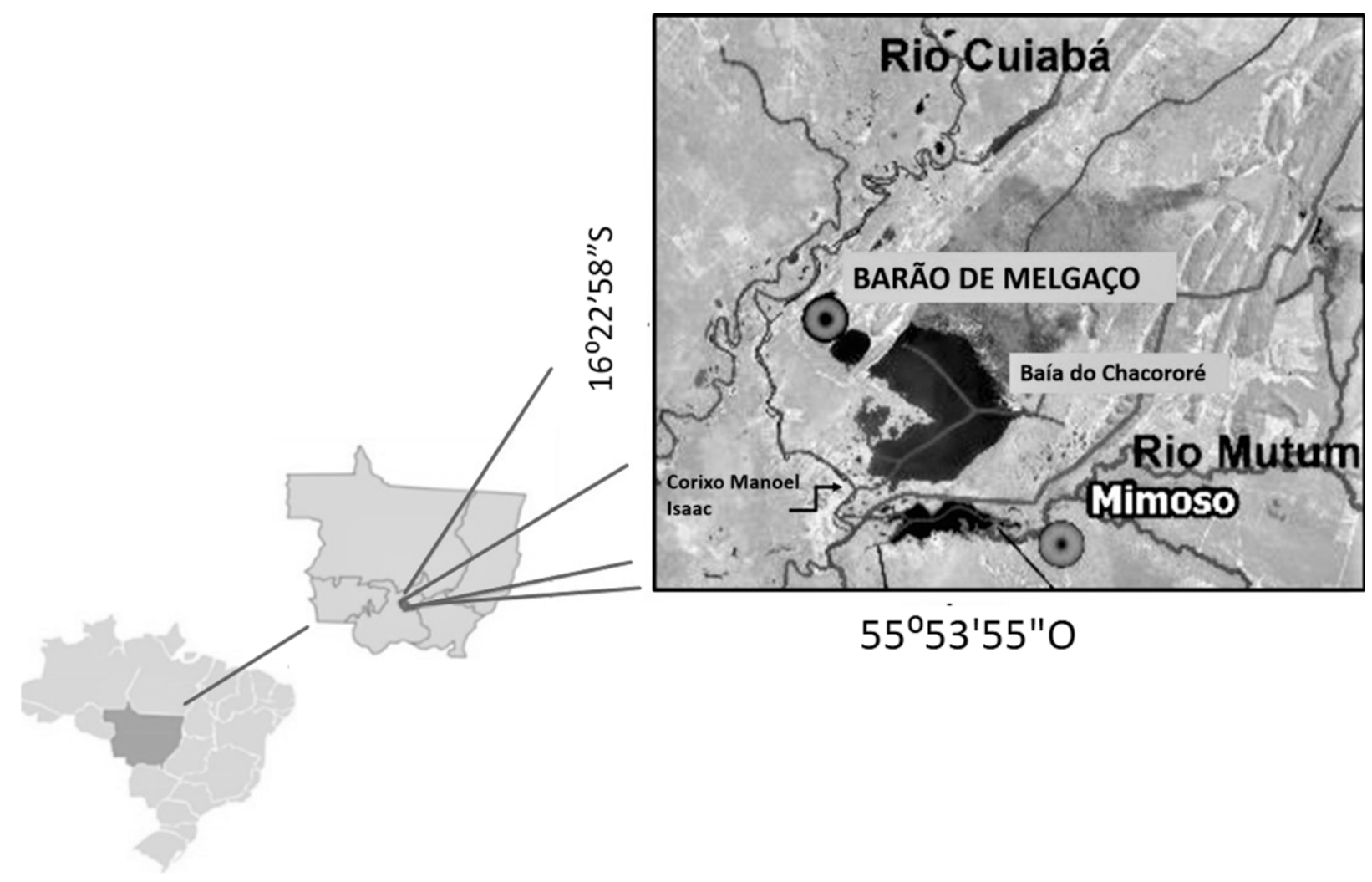

Fig. 1. Mapa de localização da lagoa do Chacororé, pantanal de Barão de Melgaço, Estado de Mato Grosso (Adaptado de Melo, 2016).

influenciam na composição e na abundância das espécies dentro do canal. As variáveis físicas analisadas (profundidade e transparência) da água foram realizadas em todas as coletas. Os valores de $\mathrm{pH}$ foram obtidos em todas as coletas, enquanto que a condutividade da água foi medida somente durante a época de enchente (outubro a dezembro).

A evolução da captura por unidade de esforço (CPUE) total foi considerada como o número de indivíduos capturados por uma bateria de redes de 60, 70, 80 e 100 mm entre nós opostos e de tamanhos diferentes, colocadas de forma transversal no canal, durante 40 minutos.

As coletas foram realizadas quinzenalmente no corixo Manoel Isaac, que liga o rio Cuiabá à baía de Chacororé, na vazante (abril a junho), estiagem (julho a setembro) e enchente (outubro a dezembro) de 1999. As capturas específicas foram consideradas para as espécies com maiores valores de CPUE (captura por unidade de esforço) em todo o período de coleta, as quais representaram $95 \%$ da frequência absoluta de todas as espécies capturadas.

As espécies que apresentaram os maiores valores de CPUE durante as coletas experimentais foram analisadas quanto aos seus movimentos migratórios dentro do canal que conec- ta o rio Cuiabá e a baía do Chacororé. As duas tendências migratórias analisadas referem-se à entrada ou saída da baía, conforme a posição que as espécies apresentaram no momento de retirada das redes de espera. As tendências dos movimentos, analisadas graficamente, foram consideradas como as diferenças de CPUE entre o movimento de saída e os movimentos de entrada. Para efeito de visualização, os valores positivos foram considerados como os movimentos de saída e os valores negativos como sendo os de entrada na baía.

Medidas de profundidade e transparência (variáveis físicas) e pH e condutividade (variáveis químicas) da água foram feitas para verificar a relação dessas variáveis com a captura das espécies. A medida da profundidade foi feita com uma régua graduada fixada na entrada do corixo; a transparência da água foi medida com um disco de Secchi; o pH foi medido com um pHmetro modelo CD-55 da marca Corning e a condutividade elétrica, por meio de um condutivímetro Corning modelo 441. Os indivíduos coletados foram levados ao laboratório para a identificação taxonômica das espécies, realizada segundo Britski et al. (2007). Os exemplares estão depositados na coleção de peixes da Universidade do Estado de Mato Grosso (UNEMAT), 
campus de Tangará da Serra, Estado de Mato Grosso.

\section{Resultados e discussão}

\section{A evolução da captura por unidade de es- forço (CPUE)}

A captura total apresentou uma tendência com os maiores valores de CPUE em dois períodos: vazante (abril a junho) e enchente (outubro a dezembro). O período da estiagem (julho a setembro) apresentou baixos valores de CPUE. No mês de abril, quando teve início a diminuição do nível da água no corixo, houve o pico máximo da captura total. No começo do mês de outubro, com a elevação do nível da água, ocorreu o segundo pico de captura, com o nível da água no canal muito inferior ao nível do primeiro pico da vazante. As frequências absolutas e relativas dessas espécies encontram-se na Tab. 1.
Do total de 38 espécies capturadas no canal, doze espécies foram as mais representativas, considerando que a seletividade do apetrecho de pesca determinou a captura dos espécimes de médio e grande porte. Pacheco \& Da-Silva (2009) em estudos da ictiofauna associada às macrófitas na baía do Chacororé, encontraram 39 espécies na cheia e 45 espécies no período da estiagem. A família mais abundante na cheia foi Sternopygidae, enquanto que na seca a dominância foi dos Characidae, todos indivíduos de pequeno porte.

As espécies mais abundantes durante todo o período de coleta foram agrupadas conforme os seus picos de abundância. O primeiro grupo é formado por espécies que apresentam dois picos de abundância, um no período da vazante e outro no período da enchente, sendo representado por Potamorhina squamoralevis (Braga \& Azpelicueta, 1983), Psectrogaster curviventris

Tab. 1. Espécies e respectivos de valores de captura por unidade de esforço (CPUE) no período de coleta.

\begin{tabular}{|c|c|c|}
\hline Nome científico & $\begin{array}{c}\text { Frequência } \\
\text { absoluta (CPUE) }\end{array}$ & Frequência relativa (\%) \\
\hline $\begin{array}{l}\text { Potamorhina squamoralevis } \\
\text { (Braga \& Azpelicueta, 1983) }\end{array}$ & 341,5 & 25,24 \\
\hline $\begin{array}{l}\text { Psectrogaster curviventris } \\
\text { (Eigenmann \& Kennedy, 1903) }\end{array}$ & 305,5 & 22,58 \\
\hline $\begin{array}{l}\text { Serrasalmus marginatus } \\
\text { (Valenciennes, 1837) }\end{array}$ & 193,0 & 14,26 \\
\hline $\begin{array}{l}\text { Triportheus paranensis } \\
\text { (Günter, 1874) }\end{array}$ & 121,5 & 8,98 \\
\hline $\begin{array}{l}\text { Serrasalmus maculatus } \\
\quad(\mathrm{Kner}, 1858)\end{array}$ & 66,5 & 4,91 \\
\hline $\begin{array}{l}\text { Schizodon borellii } \\
\text { (Boulenger, 1900) }\end{array}$ & 65,5 & 4,84 \\
\hline $\begin{array}{l}\text { Rhaphiodon vulpinus } \\
\text { (Spix \& Agassiz, 1829) }\end{array}$ & 54,5 & 4,02 \\
\hline $\begin{array}{l}\text { Pygocentrus nattereri } \\
\text { (Kner, 1858) }\end{array}$ & 37,0 & 2,73 \\
\hline $\begin{array}{l}\text { Roeboides bonariensis } \\
\text { (Steindachner, 1879) }\end{array}$ & 32,5 & 2,40 \\
\hline $\begin{array}{l}\text { Mylossoma orbignyanum } \\
\text { (Valenciennes, 1849) }\end{array}$ & 30,5 & 2,25 \\
\hline $\begin{array}{l}\text { Oxydoras kneri } \\
\text { (Bleeker, 1862) }\end{array}$ & 19,0 & 1,40 \\
\hline $\begin{array}{c}\text { Acestrorhynchus pantaneiro } \\
\text { (Menezes, 1992) }\end{array}$ & 17,5 & 1,29 \\
\hline TOTAL & 1284,5 & $94,9 \%$ \\
\hline
\end{tabular}


(Eigenmann \& Kennedy, 1903), Serrasalmus marginatus (Valenciennes, 1837), Triportheus paranensis (Günter, 1874), Schizodon borellii (Boulenger, 1900), Rhaphiodon vulpinus (Spix \& Agassiz, 1829), Roeboides bonariensis (Steindachner, 1879) e Acestrorhynchus pantaneiro (Menezes, 1992).

$R$. bonariensis teve o segundo pico de abundância no final de setembro, portanto, antes do início do período da enchente. Porém, ela foi incluída neste grupo por causa da elevação do nível da água que, embora em pequena escala, ocorreu justamente nesta data de coleta.

O segundo grupo é formado por espécies que apresentaram apenas um pico de abundância durante o período da coleta. Este grupo inclui as espécies Serrasalmus maculatus (Kner, 1858), Pygocentrus nattereri (Kner, 1858), Mylossoma orbignyanum (Valenciennes, 1849) e Oxydoras kneri (Bleeker, 1862). As duas primeiras espécies mostraram pico de abundância no período da vazante e decresceram a partir do período de seca. As duas últimas espécies apresentaram elevadas capturas apenas no período da enchente.

As espécies $P$. curviventris, $T$. paranensis, $S$. borellii e $R$. vulpinus apresentaram duas tendências de movimentos bem definidas, uma de saída e outra de entrada na enchente (Fig. 2). As quatro espécies acima apresentaram a tendência de saída no mês de maio, período em que o nível da água teve a sua maior variação de profundidade. A tendência de entrada na baía ocorreu para essas espécies no mês de outubro, quando o nível d'água no corixo começou a se elevar. A tendência de saída (no período da vazante) apresentou maiores valores de CPUE com relação à tendência de entrada na baía no período da enchente (outubro a dezembro).

As espécies que apresentaram uma única tendência nos seus movimentos foram $P$. squamoralevis, S. marginatus, $R$. bonariensis nos movimentos de saída (Fig. 3). Nos movimentos de entrada apareceram $M$. orbignyanum e 0 . kneri (Fig. 4).

Três espécies não apresentaram tendências de movimentos migratórios: $S$. maculatus, $P$. natereri e $A$. pantaneiro. Os valores de CPUE dessas espécies foram muito baixos durante os três períodos fluviométricos.

\section{Relação dos movimentos migratórios com as variáveis ambientais}

A variação sazonal da profundidade mostrou ser o principal fator de influência do comportamento migratório das espécies no Pantanal de Mato Grosso, uma vez que ela atua diretamente sobre as características limnológicas, como transparência, $\mathrm{pH}$ e condutividade da água.

Com base nos dados de variação de profundidade no corixo durante este estudo, verifica-se que quando o nível da água é mais elevado, ocorre a passagem dos peixes entre o rio e a baía e vice-versa. No início da vazante (abril),
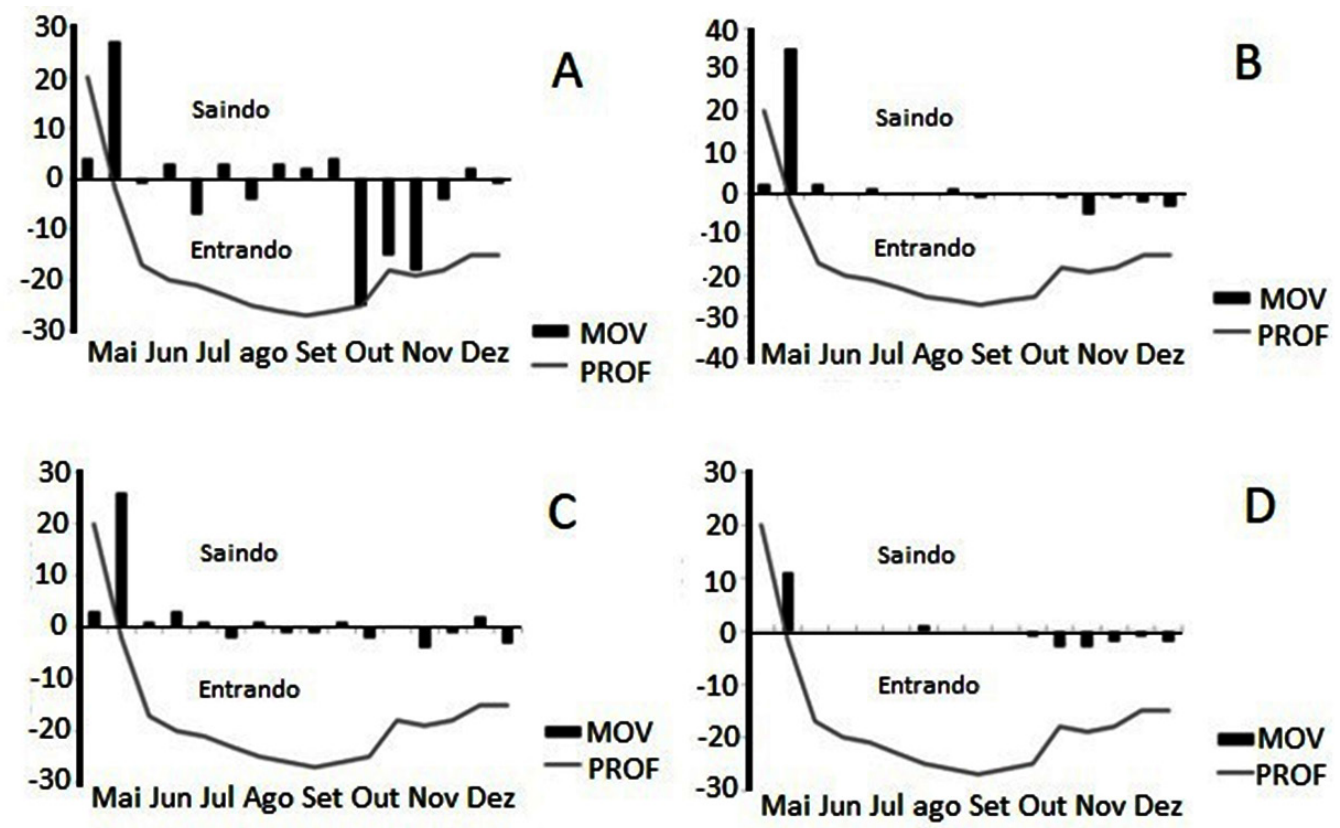

Fig. 2. Tendência dos movimentos migratórios laterais de entrada e saída na baía Chacororé: (A) Psectrogaster curviventris; (B) Triportheus paranensis; (C) Schizodon borellii; (D) Raphiodon vulpinus. MOV: movimento; PROF: profundidade. 

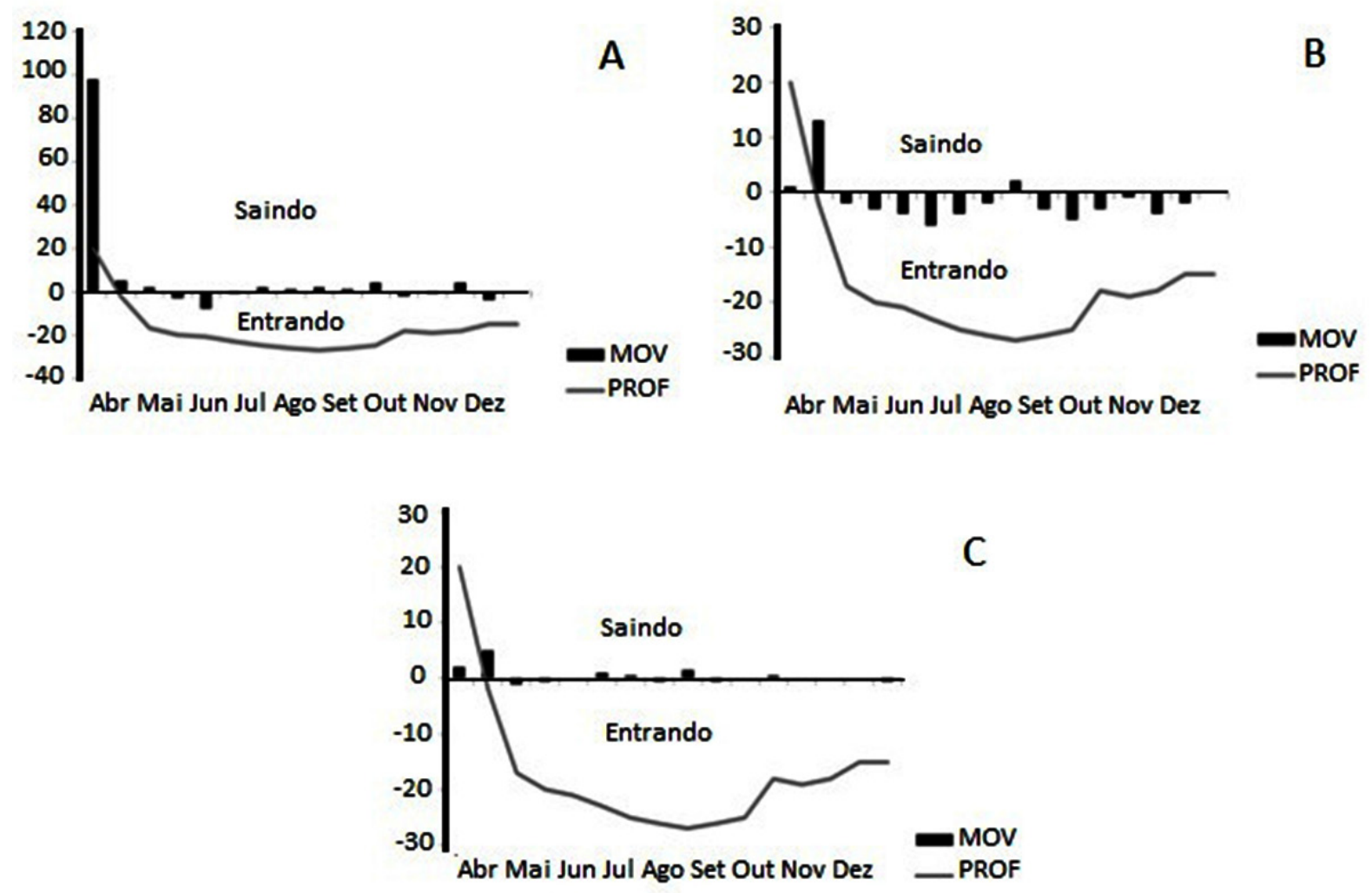

Fig. 3. Tendência dos movimentos migratórios laterais de saída da lagoa Chacororé: (A) Potamorhina squamoralevis; (B) Serrasalmus marginatus; (C) Roeboides bonariensis. MOV: movimento; PROF: profundidade.

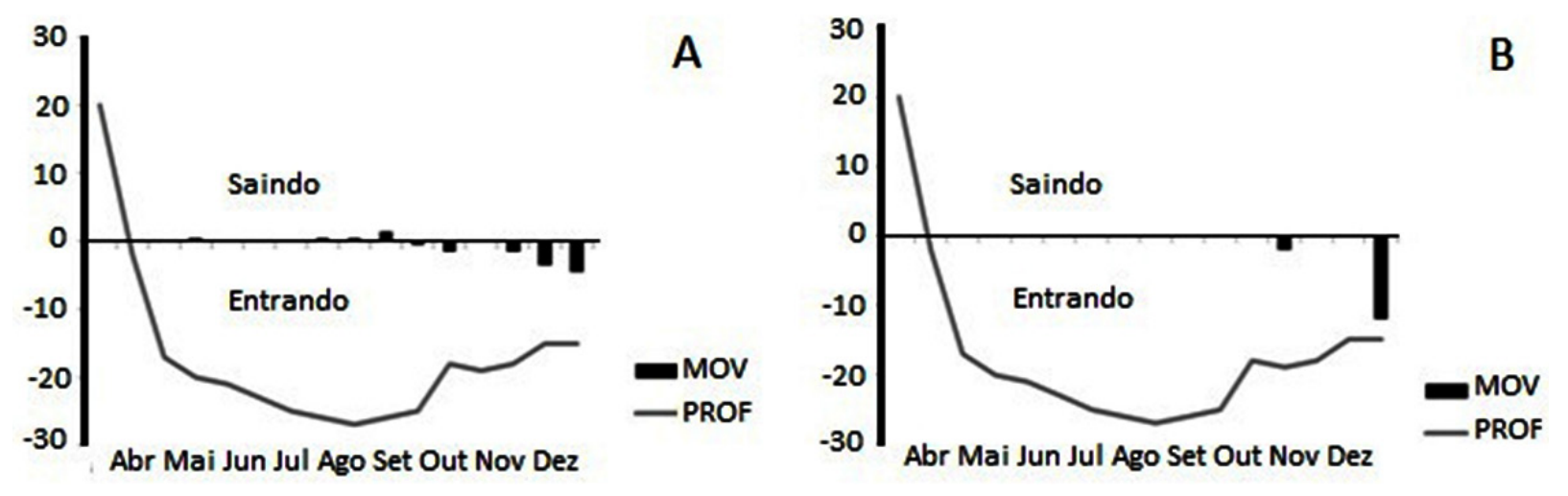

Fig. 4. Tendência dos movimentos migratórios laterais de entrada da lagoa Chacororé: (A) Mylossoma duriventris; (B) Oxydoras kneri. MOV: movimento; PROF: profundidade.

a captura é elevada até o mês de julho, e as CPUEs decrescem quando tem início o período de estiagem (julho) e ocorre a elevação do nível da água do corixo no final de setembro, uma segunda elevação na captura é verificada; porém, o sentido de movimentação da maioria das espécies é a favor da correnteza, ou seja, movimento de entrada na baía. Uma análise mais detalhada de cada espécie é fundamental para entender esta dinâmica, pois as espécies têm picos de captura diferentes ao longo do ano.

De acordo com Sobrinho \& Alves (2011), devido a sua localização, o corixo que liga a baía de Chacororé com o rio Cuiabá recebe sedimentos de diversas regiões. Os autores supracitados obtiveram maior reflectância nas imagens de satélite em decorrência do acúmulo de sedimentos suspensos do rio Cuiabá que alimenta a baia. Fantin-Cruz et al. (2008) enfatizaram que 
a maior área superficial da baía do Chacororé, quando comparado com outras baías próximas, e a conectividade constante com o rio Cuiabá permitem que ocorram trocas de matéria orgânica e inorgânica constantes entre os sistemas rio-lagoas. Ainda, segundo os autores, essa conectividade tem promovido o aporte e a deposição de resíduos sólidos originários das áreas urbanas de Cuiabá e Barão de Melgaço.

Mello (2016) destacou que a água oriunda da baía do Chacororé é predominantemente túrbida, pois recebe sedimentos do rio Cuiabá através dos canais de ligação. A autora descreve que os sedimentos do rio Mutum deixam as águas mais túrbidas na baía Siá-Mariana e contribui para a turbidez na baía do Chacororé na época chuvosa.

\section{Vulnerabilidade da baía do Chacororé}

As características morfométricas da baía do Chacororé, entre elas a sua grande área superficial $(64,92 \mathrm{~km} 2)$ fazem com que ocorram trocas permanentes entre os sistemas rios-lagoas e, além disso, ocorre entrada de material alóctone de origem da planície de inundação na época da enchente (Fantin-Cruz et al., 2008). Ainda, segundo esses autores, a constante ligação com o rio também promove o aporte e deposição de resíduos sólidos originados das áreas urbanas da grande Cuiabá e Barão de Melgaço, localizadas na região montante dessas baías.

"Considerando então a vulnerabilidade ambiental da bacia do rio Mutum e, os indicativos morfométricos da baía Sinhá Mariana, é possível afirmar que a vulnerabilidade na área dos principais cursos hídricos da bacia está gerando maior aporte de sedimentos para a baía Sinhá Mariana, influenciado na aceleração do processo de assoreamento, demonstrando assim, que as atividades econômicas quando praticadas desrespeitando a vulnerabilidade destas áreas acarretam impactos expressivos para esse sistema" (Mello, 2016).

Diniz et al. (2015) descreveram os processos evolutivos de contaminação da baía do Chacororé e concluíram que os impactos ambientais provocados por atividades antrópicas, como os poluentes oriundos dos afluentes, foram percebidos nas imagens analisadas, principalmente na época da seca. Essa constatação foi verificada em uma visita in loco na baía do Chacororé em outubro de 2018, ainda no período seco, em que a profundidade e a transparência da água estiveram muito abaixo daqueles demonstrados por Fantin-Cruz et al. (2008).

\section{Conclusão}

A migração lateral de peixes entre a baía Chacororé e o rio Cuiabá durante o estudo apresentaram maiores capturas durante os meses de abril a junho (vazante) com sentido de movimentação baía-rio. Durante a enchente (outubro a dezembro), o sentido do movimento dos peixes foi rio-baía.

\section{REFERÊNCIAS}

Bayley, P. B. 1973. Studies on the Migratory Characin prochilodus platensis Homber, 1899 (Pisces, Characoidei) in the River Pilcomayo, South America, J. Fish Biol. 5:25-40.

Britski, H. A.; K. Silimon \& B. S. Lopes. 2007. Peixes do Pantanal: manual de identificação. Corumbá: Embrapa Pantanal, 184 p.

Chapmam, D. W.; W. H. Miller; R. G. Dudley \& R. J. Scully. 1971. Ecology os fish in the Kafue river. University of Idaho Tech. Rept. FAO, Rome, FI: SF/ZAM 11 Tech. Rep. 2, 66.

Diniz, G. L.; A. Krindges \& M. O. Assunção-Jr. 2014. Processo evolutivo de contaminação da Baía de Chacororé. Proceeding Series of the Brazilian Society of Applied and Computational Mathematics, v. 3, n. 1, 2015. TrabaIho apresentado no XXXV CNMAC, Natal-RN.

Fantin-Cruz I.; S. Loverde-Oliveira \& P. Girard. 2008. Caracterização morfométrica e suas implicações na limnologia de lagoas do Pantanal Norte. Acta Sci. Biol. Sci. 30(2): 133-140.

Ferraz de Lima, J. A. 1986/87. A pesca no Pantanal de Mato Grosso (rio Cuiabá: importância dos peixes migradores) Acta Amaz. 16/17(único): 87-94.

Lowe-McConnell, R. H. 1977. Ecology of fish in Tropical waters. London, Edward Arnold Publishers, $62 \mathrm{p}$. 
Junk, J. W. 1984. Ecology of the várzea, floodplain of Amazonian whitewater rivers. From Sioli, H. In the Amazon: limnology and landscape ecology of a might tropical river and its basin. Dordrech, Dr. Junk Publishers, 763 p.

Melo, A. P. G.; G. B. M. Alves \& S. M. L. Oliveira. 2016. Uso e cobertura vegetal do solo da bacia do rio Mutum nas Zonas de Transição Aquático - Terrestre do Pantanal Norte. In: SIMPÓSIO DE GEOTECNOLOGIAS NO PANTANAL, 6., Cuiabá. Anais $6^{\circ}$ Simpósio de Geotecnologias no Pantanal. Cuiabá: Embrapa-Inpe, v. 6, p. 111-121.

Pacheco, E. B. \& C. J. Da-Silva. 2009. Fish associated with aquatic macrophytes in the Chacororé-Sinhá Mariana Lake system and Mutum River, Pantanal of Mato Grosso, Brazil. Braz. J. Biol. 69(1): 101-108.

Ribeiro, M. C. L. B. 1983. As migrações dos jaraquis (Pisces, Prochilodontidae) no rio $\mathrm{Ne}$ gro, Amazonas-Brasil. Dissertação de Mestrado- INPA/FUA, Manaus, 192 p.

Salomão, F. X. T. 1999. O rio Cuiabá como subsídio para a Educação Ambiental: Coletânea. Cuiabá, EdUFMT. p. 27-33.

Severi, W. 1999. O Rio Cuiabá como subsídio para a educação ambiental: coletânea. Cuiabá, EdUFMT, p. 65-100.

Sobrinho, J. A. F. \& M. C. Alves. 2011. Variação temporal da assinatura espectral da baía de Chacororé no Pantanal de Mato Grosso. Anais XV Simpósio Brasileiro de Sensoriamento Remoto - SBSR, Curitiba, PR, Brasil, 30 de abril a 05 de maio de 2011, INPE, p. 5255.

Val, A. L. 1996. Surviving low oxygen levels: lessons from fishes of the Amazon. In: Val, A. L.; Randall, D. J. \& Almeida-Val, V. M. F. (Ed.). Physiology and Biochemistry of the Fishes of the Amazon. Manaus, INPA, p. 59-73.

Welcomme, R. L. 1985. River fisheries Rome: FAO Fisheries Technical Papers, 330 p.
Zaniboni Filho, E. 1985. Biologia da reprodução do Matrichã, Brycon cephalus (Gunter, 1896) (Teleostei: Characidae). Dissertação de Mestrado- INPA/FUA, Manaus, 134 p.

Recebido em 14.IV.2017

Aceito em 12.III.2019 